\title{
Explorando el papel sociológico de las emociones en el movimiento social de Atenco, México
}

\section{Edith Kuri Pineda}

Universidad Autónoma Metropolitana. Unidad Xochimilco. Ciudad de México, México. kurichi1@hotmail.com

ORCID: 0000-0001-7061-6933

Recepción: 30-11-2018

Aceptación: 15-03-2020

Publicación: 08-05-2020

\section{Resumen}

En los últimos años, las emociones se han convertido en objeto de reflexión teórica y de exploración empírica en diferentes ámbitos de la vida social y política, como en el caso del papel que desempeñan en los procesos de movilización social. El presente artículo es una interpretación desde la sociología de las emociones y de la acción colectiva sobre el movimiento social de San Salvador Atenco, México, encaminado a defender el territorio amenazado por la construcción de un megaproyecto aeroportuario durante 2001 y 2002. Las relaciones sociales intra e intercomunitarias, los lazos afectivos labrados a lo largo del tiempo, así como la relación entre los pobladores y el territorio, jugaron un rol clave en la edificación de dicho movimiento. Con técnicas de investigación cualitativas, como entrevistas en profundidad y ejercicios de observación participante, se explorará la dimensión afectiva en la construcción de este actor colectivo. El agravio y la injustica fueron emociones presentes en la irrupción de este sujeto, mientras que el orgullo y la topofilia contribuyeron a mantener la movilización, además de formar parte de la identidad colectiva de los atenquenses.

Palabras clave: movimientos sociales; emociones; identidad colectiva; territorio

Abstract. Exploring the sociological role of the emotions in the social movement of Atenco, México.

In recent years, the emotions and its role in politics and social life have become a subject both of theoretical discussion and empirical exploration. One fundamental feature under inquiry is the importance of emotions play in the social protest. This article is an interpretative exercise from the sociology of emotions and collective action perspectives on the social movement of San Salvador Atenco, Mexico, whose goal was the defense of their territory threatened for the airport megaproject during the period 2001-2002. I will argue how the intra and intercommunal social relations, the affective bonds woven throughout time, 
the relationship between inhabitants and their territory, all played a relevant role collective actor building. With support on qualitative research techniques, such as semi-structured interviews and participant observation, I will explore the affective dimension in the constitutive dynamics of this collective actor. As we will see, both grievance and the feeling of injustice were emotions present at early stages of this movement, while pride and topophilia contributed to maintaining the mobilization, furthermore, these elements were part of the collective identity of the people for Atenco.

Keywords: social movements; emotions; collective identity; territory

\section{Sumario}

1. Introducción 4. Atenco: emociones en movimiento

2. El nacimiento del Frente de Pueblos en 5. Emociones, identidad y territorio

Defensa de la Tierra: perfil y trayectoria sociopolítica de un actor colectivo

6. Conclusión

3. Razones y emociones en la acción Referencias bibliográficas colectiva: algunos puntos de partida teóricos

\section{Introducción}

En octubre de 2001, el Gobierno federal encabezado por el entonces presidente de la república, Vicente Fox, promulgó diecinueve decretos expropiatorios con el propósito de construir una nueva terminal aérea en la zona oriente del Estado de México, México. Esta medida afectó a tres municipios, Texcoco, Atenco y Chimalhuacán (mapa 1). De inmediato, un grupo de ejidatarios ${ }^{1}$ y residentes emprendieron una movilización social orientada a anular dicha expropiación, organización que se desplegó tanto en la esfera legal como en la de la acción sociopolítica. El conflicto duró nueve meses y finalizó tras la decisión gubernamental de abolir el proyecto más ambicioso de esa gestión presidencial, que tenía previsto contar con inversión nacional e internacional.

El actor atenquense se ha convertido en un emblema organizativo e identitario para otros movimientos en la lucha por la defensa del territorio, además de haber sido objeto de uno de los episodios de represión estatal más notables en los años recientes en México - en mayo de 2006. El presente artículo se centrará en analizar el conflicto aeroportuario en 2001 y 2002, para lo cual se formulan las siguientes preguntas: ¿qué papel desempeñaron las emociones de los integrantes de este movimiento en el nacimiento, el mantenimiento y el

1. La Constitución mexicana de 1917, emanada de la revolución de 1910, en su artículo 27 estableció que el ejido es propiedad del Estado, el cual delegaba dichas tierras a campesinos desposeídos bajo la condición de que estas sean inalienables. En 1992, el Gobierno de Carlos Salinas efectuó una reforma constitucional que abrió la figura del ejido al mercado y, con ello, la posibilidad de venderlo o comprarlo. Esta reforma fue parte de las transformaciones estructurales del modelo neoliberal que en México comenzó a aplicarse desde 1982. 
Mapa 1. Localización del municipio de Atenco, su cabecera municipal y el polígono del proyecto aeroportuario de 2001

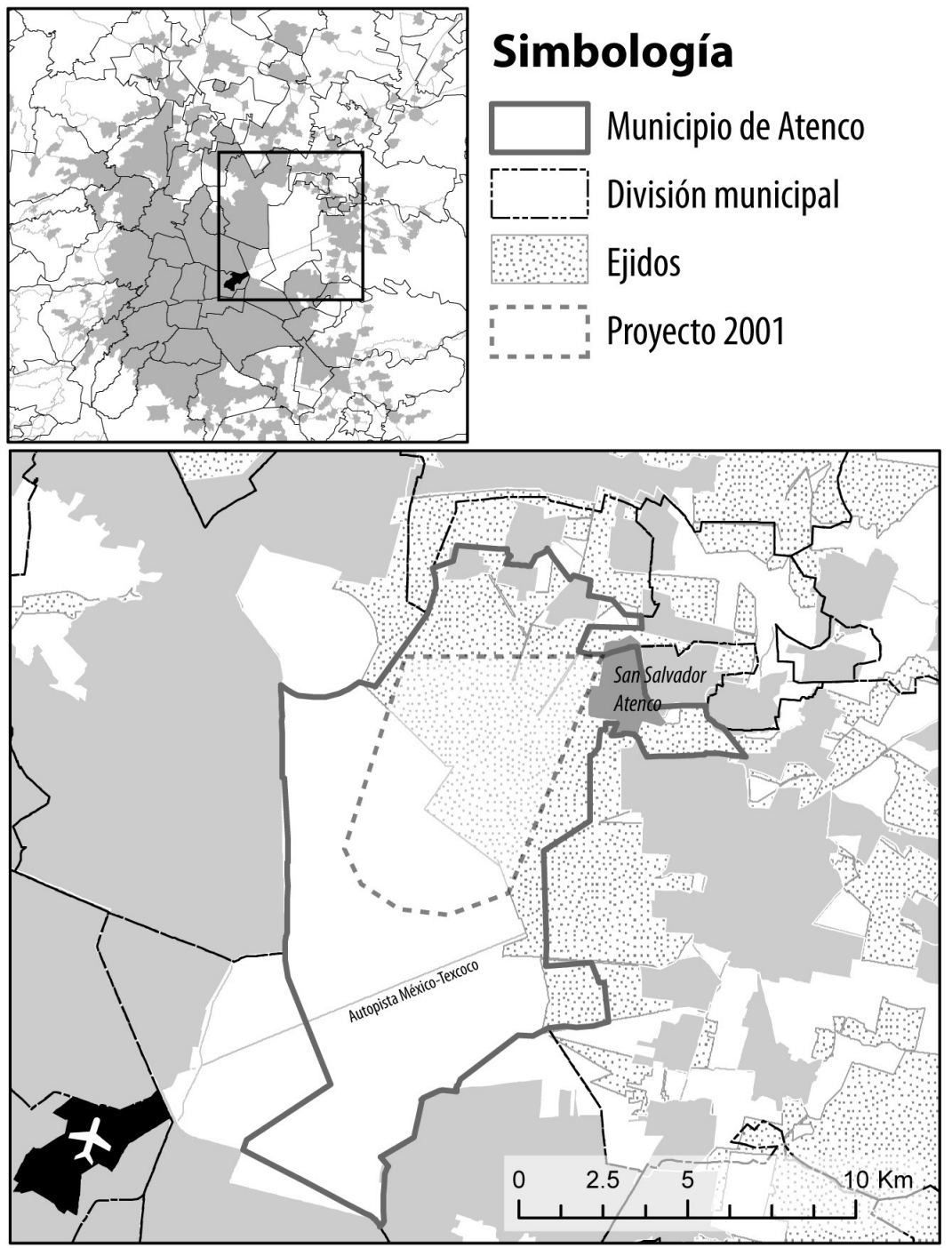

Fuente: elaboración propia a partir de la cartografía urbana de 2000 de INEGI.

desarrollo de la acción colectiva?, ¿qué tipo de emociones son?, ¿qué significa el territorio para los residentes y ejidatarios organizados en su defensa?, ¿qué relación existe entre identidad y afecto?, ¿`cómo se corporeiza dicho nexo en el actor atenquense? Para responder estos interrogantes, se realizaron dieciséis entrevistas en profundidad a líderes y bases de este sujeto, hombres y muje- 
res de diversas edades — de 2005 a 2006 —, en los pueblos de San Salvador Atenco, Nexquipayac y Acuexcomac, con el fin de analizar cómo se erigió este actor; la racionalidad subyacente a la acción —es decir, significados, valores, emociones, razones, creencias-, las disputas y los puntos de articulación en el interior del sujeto y las representaciones sobre el territorio. Cabe recalcar que se formularon preguntas en las que expresamente se cuestionó qué pensaban y sentían los informantes sobre determinados sucesos del conflicto; en otros casos, la dimensión afectiva afloraba de manera espontánea durante las entrevistas. Asimismo, se efectuaron ejercicios de observación participante en asambleas, eventos políticos y fiestas tradicionales con la finalidad de examinar y analizar las prácticas sociales y políticas, los procesos deliberativos y decisorios, así como los discursos emitidos. Ambas técnicas etnográficas partieron de la premisa de que la acción colectiva es una construcción intersubjetiva donde se imbrican ingredientes sociales, políticos y culturales - razones, valores y emociones-, y que la finalidad del trabajo de campo era rescatar la subjetividad política y las formas de relacionalidad social.

El artículo está estructurado en cuatro secciones: en la primera, se desarrollará brevemente el desarrollo del conflicto aeroportuario; en la segunda, se problematizará el papel de la razón y las emociones en los escenarios organizativos; en la tercera, se analizará, desde la sociología de las emociones y la acción colectiva, el papel que desempeñaron los sentimientos en dicha dinámica movilizatoria; finalmente, se expondrá el vínculo existente entre emociones, territorio e identidad colectiva.

\section{El nacimiento del Frente de Pueblos en Defensa de la Tierra: perfil y trayectoria sociopolítica de un actor colectivo}

Desde hacía décadas, diferentes gobiernos federales habían declarado la necesidad de erigir un nuevo aeropuerto en la Zona Metropolitana de la Ciudad de México. En octubre de 2001, el presidente Vicente Fox emitió diecinueve decretos expropiatorios que afectaban a tres municipios del oriente del Estado de México: Chimalhuacán, Texcoco y San Salvador Atenco. El proyecto fue blanco de numerosas críticas por los riesgos ambientales, urbanísticos y aeronáuticos que encerraba. Si bien la edificación de la terminal aérea podría ser en otra sede, en Tizayuca, Hidalgo, el Gobierno no consideró dicha opción. Ante tal escenario, un grupo de residentes y ejidatarios decidieron organizarse para revertir dicha decisión, que, desde un inicio, generó un sentimiento de agravio al no haber sido consultados para tal medida. La lucha se materializó en dos frentes: por un lado, el legal — con amparos interpuestos—; por el otro, la acción colectiva, que se caracterizó por desplegar diversos repertorios de movilización — marchas, barricadas, mítines, paros, asambleas y retención de funcionarios gubernamentales como medida de presión. Fue así como nació el Frente de Pueblos en Defensa de la Tierra (FPDT), organización que aglutinó a ejidatarios y habitantes de comunidades afectadas por la expropiación - como San Salvador Atenco, Nexquipayac, Acuexcomac, Tocuila, la colonia 
Francisco I. Madero y Santa Isabel Ixtapan - que, desde el inicio del conflicto, mantuvieron un rotundo rechazo a la edificación aeroportuaria y a vender sus tierras. Este sujeto se nutrió de otras organizaciones sociales existentes en la región desde décadas atrás que se movilizaban por la gestión social de servicios. Este hecho, junto con la celebración de fiestas y faenas, brindó al FPDT una experiencia organizativa medular en el momento de la resistencia en contra del aeropuerto en 2001-2002 (Kuri, 2010).

En agosto de 2002, el Gobierno de Vicente Fox decidió anular el proyecto aeroportuario ante un escenario de notable presión por parte del actor atenquense. Esta abrogación significó para el FPDT un margen de reconocimiento y legitimidad frente a otros sujetos, involucrados o no en el conflicto aeroportuario. Así, el FPDT comenzó una nueva era como gestor colectivo de demandas sociales en otras zonas del oriente del Estado de México. Es justamente bajo esta nueva coyuntura política que el pueblo de Atenco - corazón político de la organización - fue objeto de un operativo estatal en el que tomaron parte los tres niveles de gobierno —el federal, el estatal y el municipal—, el 3 y el 4 de mayo de 2006, en el que participaron más de 3.000 policías. El resultado final de la toma de este pueblo fue una serie de graves violaciones a los derechos humanos, como agresiones sexuales, detenciones arbitrarias, registros ilegales a domicilios, tortura y ataques al debido proceso. Resulta pertinente destacar que la judicialización y la criminalización de este actor colectivo fue una constante. El caso de Atenco llegó a la Corte Interamericana de Derechos Humanos y, como tal, constituye un referente sociopolítico y jurídico.

A lo largo de varios años, el municipio de Atenco vivió un proceso de urbanización en el que la cercanía con la Ciudad de México jugó un rol clave. Según cifras de los Censos de población y vivienda de 2000 y 2010 (INEGI), la población atenquense creció a un ritmo del 5,03 \% durante esta década, mientras que la vivienda lo hizo a un ritmo del 6,14 \%, dato que muestra la presión sobre la tierra y los recursos urbanos. El porcentaje dedicado a actividades primarias era del $12,5 \%$ en 1990 , del $8,19 \%$ en 2000 y del $3,8 \%$ en 2010, y las labores terciarias - comercio y servicios - eran las ocupaciones principales. Esto remite a preguntarse por qué, si un importante porcentaje de la población no se dedicaba a trabajos agrícolas, decidieron no vender sus tierras. Como se verá en los siguientes apartados, las densas relaciones identitarias y afectivas entre los atenquenses y el sentimiento de apego al territorio son parte de la respuesta.

\section{Razones y emociones en la acción colectiva: algunos puntos de partida teóricos}

Existe una amplia producción teórica sobre la acción colectiva y los movimientos sociales provenientes de diferentes tradiciones del pensamiento. Ya desde finales del siglo XIX, diversos analistas aseveraban que dichos fenómenos estaban regidos por la anormalidad y la irracionalidad, precepto que de algún modo fomentó perspectivas como la de Smelser (1962), en la que la 
conducta colectiva es síntoma de tensiones sociales irresueltas. Esta atribución de irracionalidad revelaba una omisión central: toda acción social cuenta con una intencionalidad y, por lo tanto, con una lógica inherente. La teoría de la elección racional parte de un punto seminal: toda acción individual o colectiva está guiada por una racionalidad, aserción que constituye una aportación relevante. Para este enfoque, individuos egoístas eligen racionalmente, dentro de un abanico de opciones, qué alternativa es la mejor según sus preferencias, es decir, hay una racionalidad instrumental subyacente al hacer. Como señala Paramio (2005), esta interpretación individualista representa un desafío analítico: si los individuos son egoístas y buscan obtener el mayor beneficio al menor coste posible, ¿por qué y cómo deciden participar en empresas colectivas selladas por la incertidumbre y el riesgo? Según Olson (1992), la respuesta radica en los incentivos selectivos que estimulan la acción. Por su parte, Markwell y Oliver (1993) han señalado que la existencia de una masa crítica es un vehículo que contribuye al crecimiento de la participación a partir del efecto de bola de nieve. A este tenor, Linares (2004; 2007) ha subrayado la importancia de las normas prescriptivas - incentivos materiales y sociales- y las normas proscriptivas — sanciones- en la dinámica movilizatoria, de tal forma que la participación se sostenga y no haya dimisión. Para este autor, al inicio de la movilización, el estímulo debe prevalecer por encima del castigo, el cual constituye un riesgo dadas las desigualdades de poder existentes dentro de los grupos sociales.

La mirada utilitarista e instrumental de la teoría de la elección racional ha sido criticada dada la importancia otorgada al papel de los incentivos materiales en la organización colectiva. Robles (2007) afirma que estos son insuficientes para explicar la participación y pone énfasis en los incentivos morales. Así pues, las personas se implican en dinámicas movilizatorias no por una lógica instrumental, sino por una racionalidad axiológica que involucra una concepción del deber moral. Para Abitbol y Botero (2005), el modelo de elección racional tiene varias limitaciones: omite la labor de interpretación que los sujetos efectúan; asume que la capacidad para computar las utilidades de todos los posibles resultados son ilimitadas; se han soslayado las creencias que están presentes en la dinámica decisoria —algunas de ellas de índole irracional. Estas omisiones, sin embargo, han sido subsanadas en los últimos años por algunos teóricos, como Schick, quien sostiene que, además de las creencias y los deseos que alimentan las razones de la acción, hay que considerar la interpretación del mundo como otro componente (Schick, en Abitbol y Botero, 2005).

La teoría de la elección racional permite formular varios interrogantes en virtud del acento puesto en la razón: ¿es la racionalidad estratégica la única existente en la movilización sociopolítica?, ¿qué relación hay entre razón, emociones, creencias y valores en la participación?, ¿hasta qué punto las emociones experimentadas por los integrantes de un movimiento constituyen un obstáculo en las decisiones políticas? En la labor de erigir una teoría de la acción social, Elster (2002) ha señalado la relevancia de las emociones en el comportamiento humano y la insuficiencia del modelo de coste-beneficio para 
analizarlas. Para él, lo afectivo guarda una relación estrecha con las normas sociales, los deseos y las creencias. Elster subraya que entre estas y la afectividad hay un nexo recursivo. Así, las emociones no son por sí mismas racionales o irracionales, su carácter dependerá de si las creencias que las pergeñan son racionales o no - sin soslayar que un sentimiento puede ser racional aunque la creencia que lo fundamente no lo sea y viceversa. Creencias y emociones serán racionales dada la evidencia disponible. Para Elster, aquella concepción que opone las razones con los afectos es inconsistente, de ahí que asevere que ante una situación donde el actor esté paralizado por la indefinición frente a varias opciones, las emociones pueden ayudar a decidir de forma certera. En la clasificación elsteriana, las emociones son concretas o bien son disposiciones temporales. Las primeras son respuestas como el miedo y la alegría, mientras que las segundas son propensiones a experimentar a las concretas, como la irascibilidad y el buen humor - los prejuicios entran también en esta categoría. Si bien Elster reconoce la racionalidad afectiva, sostiene que las emociones efímeras pueden obnubilar una elección racional, en tanto que las más permanentes pueden servirse de una racionalidad instrumental para la consecución de los fines del individuo: «Las pasiones de corta vida socavan la teoría del actor racional, mientras que las duraderas socavan la teoría del Homo economicus» (Elster, 2002: 368).

En su estudio sobre la disputa histórica entre albaneses y serbios, Petersen (2008) afirma que en un escenario de conflictividad política hay un uso estratégico de las emociones en aras de someter al adversario. De forma semejante a Elster, Petersen argumenta que la emocionalidad moldea las creencias - a la vez que estas pueden configurar los sentimientos-, además de hablar de emociones de predisposición que ejercen de soporte a las emociones ocurrentes. Las propuestas de Elster y Petersen representan un esfuerzo teórico sobre el rol de la razón y de la emoción en la acción social y política y rompen con falsas dicotomías. Sus aportaciones radican no solo en tender puentes entre lo estratégico y lo emocional, sino también en enmarcar la relación estrecha que hay entre cognición y afectividad. Sostengo que las emociones y las razones son formas por las cuales los individuos en interacción construimos la realidad social, la aprehendemos y respondemos a ella.

La vieja escisión entre razón y emoción —-donde esta era sinónimo de irracionalidad- lleva la impronta de la dualidad cuerpo-mente. En este artículo se parte de la premisa de que las razones, las creencias, los afectos y los valores conforman la dimensión cultural de los movimientos sociales y fungen como dispositivos semánticos y cognitivos que orientan la acción. Por consiguiente, la racionalidad subyacente a la acción colectiva está integrada por razones -incluyendo las instrumentales_, emociones y componentes axiológicos, es decir, lo expresivo no excluye lo instrumental. Así, los sujetos colectivos no solo son agentes racionales, sino también emocionales y axiológicos, en los que la movilización no solo es un medio para reivindicar y satisfacer diversas demandas, sino también un fin en sí mismo, en virtud de la experiencia sociopolítica $y$ vivencial que encierra. 
Las emociones han sido concebidas como construcciones sociales e históricas de índole cambiante. Elster establece que aunque existan afectos universales, la cultura desempeña un lugar prominente: «Si (la emoción) no pertenece al repertorio conceptual de la cultura en cuestión, no puede ser conscientemente reconocida. La cultura, por consiguiente, actúa como modificadora (ya sea como amplificadora o como freno) de las emociones» (Elster, 2002: 318). A este tenor, Hochschild (1979) señala cómo las reglas sociales configuran el sentir de los sujetos, los cuales pueden respetar o bien desafiar dicho orden normativo. Kemper (1978) ha enfatizado que la afectividad proviene de dos formas básicas de relacionalidad social: el poder y el estatus. Este autor menciona que la mayoría de los afectos son fruto de resultados reales, anticipados, imaginados o bien recordados de la interacción social. Por su parte, Collins (2009) asevera que la emoción es un incentivo para la acción social; los afectos cohesionan la sociedad, al tiempo que mueven al conflicto y ejercen de sustrato de la estratificación social.

Así, las emociones son producto de las relaciones sociales, a la vez que inciden en ellas. Un punto digno de resaltar es su carácter vinculante, tanto en el terreno social como en el político. El papel desempeñado por la afectividad no se limita a ser un simple constructo, a jugar un rol pasivo; entre el mundo social y lo emocional existe una relación de mutua influencia.

Las emociones están ubicadas en contextos culturales, políticos, sociales e históricos, además de estar presentes en los procesos de construcción de sentido. La dimensión afectiva de la realidad social es inseparable de la subjetividad, las identidades, la memoria, la corporalidad, las relaciones y prácticas sociales, lo espaciotemporal, las normas, el poder y las estructuras sociales. Reitero que hablar de la racionalidad de los actores implica incorporar no solo las razones, sino también los afectos, las creencias y los valores que en interrelación orientan el quehacer social y político de diverso calibre.

Desde esta óptica, cabe preguntarse sobre el papel que desempeña la afectividad en la dinámica de movilización sociopolítica partiendo de la premisa de que razón y emoción no son manifestaciones antagónicas, sino componentes que actúan como sextantes que guían las decisiones y la acción política y social. Durante mucho tiempo, las teorías de los movimientos sociales obviaron lo afectivo - como la de la movilización de recursos, cuya premisa vertebral se fundamentó en la racionalidad inherente a las decisiones de los actores colectivos; o bien la accionalista, cuyo interés, si bien se centraba en estudiar las identidades, no efectuó un análisis pormenorizado de este fenómeno. Como bien apunta Jasper (1998), la perspectiva que más se acercó al plano emocional de la acción colectiva fue la teoría del enmarcado, la cual, sin embargo, se circunscribió a explorar el plano cognitivo de los sujetos organizados. Como se sabe, este enfoque se ha centrado en explorar cómo los actores interpretan y resaltan determinados acontecimientos, además de buscar enmarcar las causas de su lucha organizada. En los tres tipos de enmarcado señalados por Snow y Benford (2006) — marcos de diagnóstico, marcos de pronóstico y marcos de motivos-, no resulta difícil colegir que lo emocional es un elemento trans- 
versal. Así, interpretar y significar un determinado hecho como un problema y atribuirle a alguien la responsabilidad —labor de significación sin la cual no habría dinámica movilizatoria—; idear qué hacer para solucionar dicha problemática y erigir los objetivos de la acción y el porqué de la movilización -factor imprescindible, dado que la construcción de la acción colectiva no solo requiere del reconocimiento de un problema, la asignación de culpables y las estrategias para dirimirla, sino también motivos para edificarla - son ejercicios que suponen no solo el despliegue de razones, sino también de emociones y valores. En otras palabras, la interpretación de la realidad y la toma de decisiones sociopolíticas encierran un trabajo axiológico y afectivo.

Uno de los conceptos emblemáticos de la teoría del enmarcado donde explícitamente está la variable emocional es el marco de injusticia, facturado por Gamson (1992). Esta noción constituye un esfuerzo reflexivo en el que se plantea cómo los miembros de los movimientos sociales significan un hecho como injusto de acuerdo con la existencia de códigos morales preexistentes. Según este pensador, los marcos de injusticia deben ser capaces de generar indignación no solo entre los integrantes del sujeto colectivo, sino en la audiencia, en los posibles aliados, lo cual implica que la edificación social de sentimientos en parte está orientada a provocar solidaridad y empatía, afectos de gran valor en los procesos de organización colectiva. La resonancia emocional de los marcos de injusticia será mayor si los miembros de los movimientos dan rostro a quien consideran el culpable de aquello que desencadena la movilización. En virtud de lo anterior, es posible señalar que entre emociones y ejercicio cognitivo hay una relación estrecha y de mutua incidencia, factores que orientan la acción política y social.

Los movimientos sociales son un espacio de interacción social y simbólica en el que se erigen, se comparten, se sobreponen y se transforman emociones de diverso talante: miedo, orgullo, solidaridad, apego, vergüenza, alegría, agravio, placer, tristeza, esperanza, enojo, indignación, entre otras. Dichos afectos están presentes en todas las etapas de la movilización, durante su construcción, reclutamiento, desarrollo, repliegue y desarticulación, así como en la construcción de los objetivos de la lucha. Sostengo que la labor emocional se despliega en dos dimensiones interrelacionadas: aquella donde a partir de las relaciones cara a cara los miembros de los movimientos experimentan diversos sentimientos; $y$ aquel plano en el que los actores colectivos, a partir de su discurso y su hacer, generan emociones en la audiencia, así como en sus propios adversarios. En otros términos, el campo de confrontación tejido entre los sujetos colectivos y sus oponentes es un terreno pergeñado no solo por ingredientes políticos, sino también afectivos. Siguiendo a Kemper (2001), se puede aseverar que las emociones constituidas en un campo de confrontación encierran relaciones de poder - por un lado, la que hay entre el movimiento y sus oponentes; por otro, la existente dentro del mismo actor - y relaciones de estatus — donde los actores voluntariamente cumplen con los intereses o deseos de otros; los lazos de estatus son comunes dentro de los movimientos sociales. Como bien recalca Kemper, tanto el poder como el estatus no son expresiones estáticas, sino 
dinámicas, condición que compete también al plano afectivo. En el siguiente apartado se analizará el rol que jugaron las emociones en la construcción y el mantenimiento de la lucha atenquense.

\section{Atenco: emociones en movimiento}

El justo enojo que pone fuego en el vientre y acero en el alma.

GAMSON

Resulta fundamental aclarar que ningún movimiento social es producto exclusivo de factores emocionales; asumirlo supone una lectura reduccionista sobre un fenómeno que se distingue por ser multidimensional, en el que convergen ingredientes políticos, culturales e históricos. Como se ha señalado, las emociones, los valores y los significados comprenden la dimensión cultural de la acción colectiva.

La existencia de antecedentes organizativos en la zona oriente del Estado de México, la construcción de una experiencia organizativa — labrada por fiestas tradicionales y religiosas - y la memoria colectiva de despojo y agravios - constituida por eventos de despojo de tierras en el pasado en esta zonafueron elementos que facilitaron la articulación del movimiento atenquense. En el conflicto aeroportuario de 2001-2002, el hecho de que los ejidatarios jamás hubieran sido consultados por ningún nivel de gobierno sobre la edificación aeroportuaria fue una fuente seminal de agravio. El punto fundamental que dio pie a la irrupción de este sujeto fue la promulgación de diecinueve decretos expropiatorios, en octubre de 2001, que fueron interpretados por los atenquenses como una amenaza a su territorio. Este evento constituye lo que Jasper (1998) ha denominado shock moral, el cual representa el primer paso para el reclutamiento y ocurre ante un hecho sorpresivo, inesperado, que genera agravio, de tal modo que incide en la decisión de participar en la acción colectiva tengan o no los individuos experiencia política. Al respecto, dan su testimonio dos habitantes de San Salvador Atenco, el pueblo que fue el núcleo de la resistencia:

Le dije a mi esposo: «¿Qué crees? Que ya nos van a quitar la casa, los terrenos». Él me preguntó el porqué. Yo le dije que sí era cierto, que ya había caído lo de la expropiación. Le dije: "Yo ya me voy». I agarré un palo y me fui. (...) Decidimos irnos a la carretera, en eso venían trabajadores de la presidencia municipal, y pues como que en esos momentos una se ciega, de por sí soy muy chillona, el caso es que una señora gritó: "Ellos son los que saben del problema, son los que vendieron nuestras tierras». (...) Así que desde que salió el decreto yo comencé a participar. (Entrevista a Epifania, archivo personal, 3 de febrero de 2006)

Llegué a casa de mi papá, lo vi muy preocupado, y que me dice: «¿Tú crees que van a hacer un aeropuerto y me van a quitar el terreno?». Pasaron dos o tres 
días y a mi hermano, el más pequeño, lo vi muy preocupado, se llevó la mano a la frente, a punto de llorar, y me dijo: «Me van a quitar mi casa; mi casa no es un palacio, pero me ha costado mucho esfuerzo. Tengo dos hijos, ‘a dónde me voy a ir?». Él traía unos planos del aeropuerto, de carreteras, fue cuando me preocupé. Ya que nos fuimos informando y nos dimos cuenta, les dije a mis hermanos: «¿Saben qué? Yo creo que hay que participar, vámonos, hay que participar, unidos tenemos que lograr algo y, si no, pues mínimo que nos escuchen». (Entrevista a Ana María, archivo personal, 28 de diciembre de 2005)

El shock moral experimentado por los integrantes del movimiento social en contra del aeropuerto es una emoción disruptiva fundamentada en la existencia de códigos morales confeccionados a lo largo del tiempo. Este concepto equivale a lo que E. P. Thompson (1981) concibió como conciencia afectiva y moral, la cual es configurada a partir de las condiciones materiales de vida de los actores. El agravio, la indignación y el sentimiento de injustica vividos por los atenquenses son emociones morales que se sustentan en nociones socialmente labradas sobre el bien y el mal, lo justo y lo injusto. Como tales, constituyeron uno de los varios elementos que coadyuvaron a la movilización, tal como se puede ver en los testimonios citados. Este tipo de emociones surgen cuando se interpreta que un orden social y moral ha sido conculcado. Jasper (1998) sostiene que los valores son sensibilidades morales que se manifiestan a través de los sentimientos; mientras que Collins (2009) afirma que son cogniciones embebidas de emociones. Por lo tanto, los valores y las emociones son constructos culturales con un claro revestimiento cognitivo.

No obstante, resulta relevante puntualizar que el shock moral no equivale a la acción colectiva: no todos los que han significado un hecho como injusto deciden movilizarse, para ello se requiere que los sujetos atribuyan responsabilidad a quien es considerado como causante del agravio y, con eso, dirigir su enojo hacia alguien —además de redes sociales que articulen la acción. En Atenco, los miembros del FPDT otorgaron dicho rol no solo al Gobierno federal, al estatal y al municipal, sino también a los simpatizantes e integrantes del Partido Revolucionario Institucional (PRI) en el ámbito local, dispuestos a vender sus tierras, con quienes en muchas ocasiones se sostenía una relación de parentesco. Este hecho tuvo un coste emocional notable, al significar la división de familias y del grueso de la comunidad. Paralelamente a este proceso, en Atenco - como en otros muchos actores sociopolíticos — la articulación de la acción colectiva implicó la creencia, la certeza, de tener la razón al defender el territorio. Se trataba de una reivindicación sobre la superioridad moral frente al adversario, el cual es descalificado en el terreno axiológico:

Mi hermano me decía: «Es que se trata del Gobierno y él va a hacer el aeropuerto». Pero como nosotros, los que estábamos en contra, como ya íbamos abriendo camino, pues yo sentía que íbamos a ganar (...). Yo decía, aunque haya muertos, vamos a ganar, con esa seguridad. Mis padres me decían: «Piensa en tus hijos, te van a matar». Yo contestaba: «Pues por ellos aquí ando, por mi familia, y aunque no tuviera hijos, pues igual lucharía, por mí misma». 
Hasta ahorita, mi papá, que es una persona grande, ha estado con nosotros: con la razón. ¿Por qué nos apoya mi padre? Porque él sabe que estamos en lo justo, que estamos defendiendo lo que nos corresponde. (Entrevista a Josefina, archivo personal, 12 de febrero de 2006)

Este testimonio trasluce otro factor sin el cual no habría movilización social: la agencia. Esto significa que la construcción de sujetos colectivos supone que los individuos, al decidir participar, ejercen y experimentan la capacidad de incidir y cambiar la realidad. Dicha decisión implica asumir una postura política y axiológica donde la confianza hacia el potencial de la propia acción resulta clave.

El shock moral vivido por los miembros de la lucha en contra de la edificación aeroportuaria se forjó en la existencia de un conjunto de sentimientos vinculados al territorio y el orden social fraguado en él - y en relación con él一, espacio construido por sus habitantes. En suma, así como no puede haber shock moral sin que existan valores, tampoco sin que haya afectos que sirven de sustrato para la disrupción del shock moral, aserción que será más adelante retomada. A este tenor, sostengo como hipótesis que el impacto emocional y axiológico causado por los decretos expropiatorios tiene de trasfondo el quebrantamiento de la vida cotidiana, de esa noción de «normalidad», sin la cual la vida social simplemente no sería factible. No sobra subrayar que la cotidianeidad es un plano de la existencia en el que se erige y se reproduce el mundo social en la medida en que supone reglas sociales, rutinas, estructuras, prácticas, formas de relacionalidad, representaciones sociales, etcétera. La vida cotidiana y su orden de normalidad representan esa dimensión existencial que no es cuestionada y que, por ende, otorga un sentimiento de confianza seminal, estructural, de seguridad de que las cosas son así y no de otro modo, y de que continuarán siendo de esa forma. Si bien la confianza y la incertidumbre son reversos de una misma moneda, la primera reviste de una importancia vital dado su carácter constitutivo del orden social:

La confianza es un ingrediente indispensable en la coordinación de nuestras acciones y nuestros afectos dentro de los márgenes que establecen las instituciones y los referentes normativos. Experiencia y acción en el mundo, afectividad e interacciones, recursos y procedimientos normativos para el funcionamiento general, son tres ámbitos que dan un sentido particular a la confianza: una condición de posibilidad para la vida social resistente a desaparecer. Su pérdida puede ser crítica pero no total, pues sin ella es impensable hacer sociedad, relacionarnos con otros, especialmente en circunstancias difíciles o devastadoras. (Sabido, 2012: 90)

La ruptura de la cotidianeidad y del sentimiento de confianza son parte intrínseca de los escenarios de conflictividad sociopolítica y acción colectiva: «Se rompía la vida normal, ya estábamos acostumbrados a una vida familiar, en pareja, los domingos y demás, y de pronto todo se rompe. Mi marido, que se oponía a que yo participara en el movimiento, lo veía: ya no iba a estar yo 
en la casa, todo iba a cambiar, y así fue» (entrevista a Ana María, archivo personal, 28 de diciembre de 2005). Cabe resaltar que justamente la edificación de la vida cotidiana es un proceso emocional — sentimientos como seguridad, tranquilidad y confianza la acompañan-, y cuando dicho plano se fractura, se generan emociones de gran dramatismo e intensidad, ante el riesgo de quebrantar un sentimiento de banalidad, de estar en el mundo, como Collins ha aseverado (2009); o bien el socavamiento de la seguridad ontológica, como diría Giddens (1998). Ante esta nueva coyuntura, los actores sociales se ven impulsados a erigir otra "cotidianeidad» y, con ello, otra forma de construir y apropiarse del espacio y el tiempo. En el caso de Atenco, esta apuesta fue en aras de defender una forma de organización social anclada en el espacio.

Así, el shock moral encerraba incertidumbre, miedo, rabia, agravio, angustia y zozobra, ante los decretos expropiatorios. Estos aguijonazos afectivos, no obstante, no solo fueron vividos por los atenquenses a raíz de la expropiación. Momentos clave en el transcurso del conflicto hicieron detonar, de nueva cuenta, dicha emoción moral: la reprimida marcha del 14 de noviembre de 2001 hizo que se experimentara miedo e inseguridad; también la posible entrada del ejército a las comunidades para desalojarlas en julio de 2002, y ante el fallecimiento de un integrante del FPDT a causa de la coerción y la toma de San Salvador Atenco por parte de la policía federal y local en mayo de 2006. En resumen, la represión representa una fuente relevante de shock moral.

Por otra parte, todo movimiento social constituye una esfera de interacción social y, en consecuencia, un ámbito de interacción afectiva. Es por esta razón que sostengo que los movimientos sociales son espacios donde se erige lo que Collins (2009) ha concebido como rituales de interacción, los cuales están compuestos por cuatro ingredientes imbricados: a) reunión corporal; b) demarcación frente a otros; c) foco de atención coincidente; d) estado emocional compartido. Para este sociólogo, las emociones no solo son componentes de todo ritual de interacción - desde el encuentro entre dos amigos hasta un concierto de música donde se congregan multitudes-, sino también su resultado.

Todo ritual de interacción genera afectos entre sus participantes: energía emocional individual — confianza, contento, fuerza, entusiasmo e impulso para la acción-; solidaridad; símbolos que representan al grupo y sentimientos de moralidad, o sea, la sensación de que sumarse al grupo, respetar sus símbolos y defenderlos frente a la transgresión es hacer lo correcto, situación que va de la mano con la noción de que otros cometen actos de vileza moral al conculcar la solidaridad grupal o sus representaciones simbólicas. En el caso de Atenco, la participación en el movimiento implicó experimentar diversas escalas de energía emocional. El símbolo en cuestión fue el territorio - durante la etapa de movilización también se gestaron más emblemas, como canciones, consignas y otros actos performativos- así como la certeza axiológica de que su defensa era lo correcto. La relevancia de los rituales de interacción comporta que:

Una lograda acumulación de coordinación emocional mediante un ritual de interacción (RI) crea sentimientos de solidaridad. Las emociones ingredientes 
de los RI son pasajeras; no obstante lo cual su efecto es una emoción duradera: los sentimientos de adhesión al grupo reunido con ocasión de un ritual. La tristeza es la emoción transitoria del ritual fúnebre, pero su labor ritual primera es engendrar solidaridad grupal o restaurarla. Los ingredientes emocionales de una fiesta pueden ser de cordialidad y de sentido del humor, pero su resultado duradero es el sentimiento de membresía en un grupo de estatus. Denomino energía emocional a esos efectos perdurables. La EE es una variable continua que recorre desde el ápice supremo de la confianza, el entusiasmo y el sentirse a gusto consigo mismo, pasando por el anodino término medio de la normalidad, hasta la sima de la depresión, la deprivación de la voluntad de iniciativa y los sentimientos negativos hacia uno mismo. (Collins, 2009: 148)

De esta manera, los repertorios de confrontación desplegados por el actor atenquense — marchas, mítines, asambleas, retención de funcionarios gubernamentales, bloqueos carreteros, paros - constituyen rituales de interacción donde había copresencia física, construcción intersubjetiva de emociones de diverso calibre y un foco de atención común. Bajo la propuesta heurística de Collins, se puede afirmar que la energía emocional experimentada por los miembros de la acción colectiva en contra del aeropuerto - resultado de numerosos rituales de interacción-comprendía un gradiente afectivo que, pese a su volatilidad, contribuyó a (re)crear un sentimiento de pertenencia y de solidaridad: «Las marchas eran muy festivas... Cuando el 14 de noviembre, allá en la Ciudad de México, cuando llegábamos al Zócalo, estábamos todos muy animados, entrábamos gritando y todo. Yo me sentía orgulloso, pues llevaba la bandera y me sentía orgulloso, iba a caballo, sentía bonito» (entrevista a Claudio, archivo personal, 5 de marzo de 2006). En esta misma sintonía, habla otra participante del movimiento en contra del aeropuerto:

En todo lo que vivimos hubo momentos de alegría, de tristeza, de rabia. Cuando íbamos a algunas marchas, había unos desgraciados que nos aventaban agua desde los edificios. También nos mentaban la madre. Pero hubo cosas muy bonitas que vivimos. De mi familia, anduvimos tres hermanos en la lucha, de los nueve que somos en total. Uno que no vivía acá pudo ver algunas películas que se hicieron de la lucha (en contra del aeropuerto), y él se emocionó mucho. Me comentó que se notaba que habíamos sufrido mucho: la tristeza, las lágrimas. Me acuerdo que cuando se ganó, cuando se canceló el proyecto, le dije a mi hija: "Creo que ya ganamos, hija». Ella me dijo que sí. Me fui al centro del pueblo, varios me empezaron a abrazar y todos me dijeron: "Yo creo que esto se logró gracias a las lágrimas». Fuimos a hacer un recorrido a varios pueblos de la zona. Yo me he encontrado con otras señoras que me llaman «talibana»y yo les contesto que a mucha honra, porque no soy agachona, yo luché por lo que nos correspondía. (Entrevista a Epifania, 3 de febrero de 2006)

Es importante señalar que previo al conflicto aeroportuario, en los pueblos afectados por la expropiación aeroportuaria, la densidad organizativa en gran parte se labró gracias a la existencia de diferentes rituales de interacción, configurados por la costumbre local. En este sentido, hay que recordar que para 
Collins estos están condicionados por dos variables centrales: el poder y el estatus - este último, definido no como jerarquía, sino como pertenencia-; aserción semejante a la de Kemper (2001), ya referida en páginas precedentes. En Atenco, dentro de los rituales de interacción erigidos, las fiestas religiosas intra e intercomunitarias y las faenas - $\mathrm{O}$ sea los trabajos colectivos realizados en aras de construir alguna obra pública - ocupan un lugar medular. Dichos rituales han constituido una esfera de interacción social y emocional que a la larga se ha reflejado en la construcción de un sentimiento de pertenencia a las comunidades y de solidaridad. Este hecho — siguiendo la lógica de Collinsrevela que son rituales de interacción exitosos. Una vez que se promulgaron los decretos expropiatorios, los repertorios de confrontación desplegados constituyeron nuevos rituales de interacción donde la corporalidad, la afectividad, los focos de atención común y la defensa de aquello que se consideró que había sido transgredido — un orden social corporeizado en el territorio- estaban imbricados.

La experiencia de participar en un movimiento social representa un terreno de energía emocional con una dilatada fluctuación: desde aquellos sentimientos de un alto nivel de energía — como la alegría - hasta aquellos de un bajo plano - como la tristeza. Los cambios en la energía emocional son fruto de las interacciones subjetivas dentro del actor, las relaciones con el adversario y con la audiencia, entre otros factores propios del desarrollo del conflicto sociopolítico. Esto denota el carácter dinámico de la construcción y reconfiguración afectiva. Jasper (2012) ha efectuado una taxonomía de los sentimientos en un escenario de acción colectiva, de acuerdo con su duración y estabilidad. Así, hay emociones reflejas — reacciones al entorno físico y social inmediato, como el miedo, la alegría, la sorpresa, el disgusto-, estados de ánimo — que perduran en el tiempo y se distinguen por carecer de objeto y por pergeñar las emociones reflejas, a la vez que son condicionadas por ellas-, pulsiones - respuestas corporales difíciles de soslayar como el deseo sexual o la necesidad de dormir-, las emociones reflexivas — apego, lealtad o aversión dirigidos no solo a humanos; este tipo de afectos va más allá de ser evaluaciones de corto plazo; el amor, la confianza, la admiración, la simpatía, el respeto, entran dentro de esta modalidad - y finalmente las emociones morales — aquellas basadas en códigos axiológicos.

Algunas de las emociones explicitadas por los actores durante las entrevistas realizadas y las conversaciones informales son: indignación, enojo, miedo, tristeza, sorpresa, orgullo, esperanza, confianza, desconfianza, lealtad, cariño, solidaridad, optimismo, alegría, apego al lugar — que en adelante denominaré topofilia - y empatía. Varios de estos afectos fueron experimentados de manera simultánea, mientras que en ciertas circunstancias unos fueron reemplazados por otros. La indignación, el agravio y el sentimiento de injusticia son emociones morales - constitutivas del shock moral - que estuvieron presentes al inicio del conflicto y que pueden ser identificadas como parte de los detonadores en el proceso de reclutamiento y participación en el movimiento - junto con la atribución de culpa a alguien. Otros sentimientos fueron vividos durante todo 
Cuadro 1. Tipología de emociones y su manifestación temporal

\begin{tabular}{|c|c|c|c|c|c|}
\hline \multirow[b]{2}{*}{ Tipo de emoción } & \multirow[b]{2}{*}{ Emoción } & \multicolumn{4}{|c|}{ Temporalidad con relación a la vida del movimiento } \\
\hline & & Antes & Inicio & Durante & Después \\
\hline \multirow[t]{3}{*}{ Emoción refleja } & Alegría & & & & \\
\hline & Miedo & & & & \\
\hline & Tristeza & & & & \\
\hline \multirow[t]{5}{*}{ Emoción reflexiva } & Apego al lugar (topofilia) & & & & \\
\hline & Cariño & & & & \\
\hline & Confianza y desconfianza & & & & \\
\hline & Lealtad & & & & \\
\hline & Solidaridad & & & & \\
\hline \multirow[t]{4}{*}{ Estado de ánimo } & Esperanza & & & & \\
\hline & Optimismo & & & & \\
\hline & Orgullo & & & & \\
\hline & Satisfacción & & & & \\
\hline \multirow[t]{2}{*}{ Shock moral } & Indignación y agravio & & & & \\
\hline & Sorpresa & & & & \\
\hline Shock moral; emoción refleja & Enojo & & & & \\
\hline
\end{tabular}

Fuente: elaboración propia.

el conflicto aeroportuario; mientras que hay afectos vinculados a un ejercicio memorístico sobre qué significa haber participado en este sujeto colectivo. Por otra parte, ciertas emociones entran en la clasificación de estados de ánimo, de componentes del shock moral, y otras son de índoles reflejas y reflexivas (ver cuadro 1). De acuerdo con la tipología de Jasper (2012) ya señalada, se presenta el citado cuadro considerando la variable temporal de las emociones a lo largo del conflicto. Como se verá, algunos de los afectos estables y duraderos ejercieron de sustrato para la irrupción de sentimientos diferentes.

Es necesario resaltar que así como hay emociones que pueden alentar la acción colectiva, existen las que pueden inhibirla, como el miedo y la impotencia. No obstante, resulta relevante destacar que el temor a la represión o al estigma de formar parte de una lucha sociopolítica no necesariamente desmoviliza a los actores: el miedo puede mutar en ira, afecto que puede propulsar la acción colectiva. El concepto de trabajo emocional labrado por Hochschild (1979) alude justamente a cómo las emociones pueden ser contenidas y, en ocasiones, modificadas de tal forma que la movilización se cristalice. El siguiente testimonio ilustra lo anterior:

Yo creo que el miedo se siente al principio, está uno frío, y está uno pensando ¿qué irá a pasar? Pero ya cuando estás en bola y gritas, te armas de valor (...). La gente se llenó de ira, de coraje y empezó a luchar más. Yo admiro mucho a la gente de Acuexcomac, decidida y muy valiente. Fue el odio de que ellos vieran cómo les golpeaban a su gente lo que los empujó. Yo también me indigné, dije: ¿̨por qué? El Gobierno da órdenes nomás para golpear, el ejército está 
para proteger a la ciudadanía no para golpear. Pero así son nuestros gobiernos de injustos. (Entrevista a Claudio, 5 de marzo de 2006)

Uno de los componentes inherentes a la construcción de los movimientos sociales es la solidaridad. Desde diversas ópticas teóricas, esta ha sido considerada como un rasgo constitutivo de la acción colectiva. En el caso del sujeto atenquense, es posible deconstruir diversos tipos de solidaridad: la existente previa al conflicto aeroportuario, en la que habitantes de los pueblos edificaron densos lazos sociales a través de rituales de interacción de diversa índole donde el apoyo y la reciprocidad jugaban un papel importante; la que se construyó en el seno del movimiento social en contra de la expropiación y, finalmente, la brindada por otros actores colectivos a la lucha de Atenco en contra del aeropuerto. En parte, esta última modalidad fue una respuesta ante las muestras de apoyo que ejidatarios y habitantes dieron previamente a otros movimientos sociales.

Siguiendo la huella interpretativa de Durkheim, Collins ha puesto énfasis en el papel vertebral que tiene la solidaridad en los procesos de cohesión social, afirmación que posibilita colegir que esta expresión afectiva tiene un carácter vinculante. Sostengo que existe una relación cercana entre solidaridad, indignación y empatía: me solidarizo con otro en función de que sus condiciones sociales de vida me generan indignación, lo cual denota mi capacidad de ponerme en su lugar, es decir, de experimentar empatía. Butler (2006) ha puntualizado cómo el duelo tiene no solo una naturaleza vinculante, sino que va más allá del ámbito privado y, por tal razón, puede tener un carácter politizante. Bajo esta premisa, la empatía constituye un puente emocional que conecta a los sujetos sociales. En síntesis, emociones como la solidaridad, la indignación y la empatía son expresiones subjetivas con un potencial vinculante identificable en los procesos de movilización sociopolítica.

Desde hace décadas, la sociología de la acción colectiva se ha abocado a comprender el porqué los individuos se involucran en ella, pese a los costes y los riesgos que encierra. La sociología de las emociones ha ofrecido una respuesta plausible: a pesar de la incertidumbre, la ansiedad, el miedo y la tristeza, participar en una movilización social puede ser una fuente de satisfacción individual y colectiva. Se trata del placer de la protesta, donde la reivindicación axiológica, las redes de solidaridad y los procesos identitarios coadyuvan a gestar un sentimiento de alegría, satisfacción y orgullo: «Me gustaría decir que en mi persona hay un gran gusto por servir al pueblo (...), me da mucho gusto, mucha satisfacción por estar sirviendo al pueblo» (entrevista a Josefina, archivo personal, 12 de febrero de 2006). En esta dinámica, actos performativos como cantar, gritar consignas, bailar, juegan un papel importante. Cada pequeña victoria en el terreno de la confrontación política es una fuente de satisfacción y de confianza — de alta energía emocional—, lo cual representa un referente relevante para los sujetos colectivos a la hora de pensar acciones y estrategias futuras. En Atenco, el hecho de conseguir que el Gobierno federal decidiera anular el proyecto aeroportuario, tras nueve meses de intensa con- 
frontación, constituyó un hito político, axiológico, memorístico y afectivo para los miembros de esta lucha. La confianza obtenida, la esperanza, la generación de expectativas, la asunción de agencia y el reconocimiento de legitimidad por parte de otros actores marcaron la nueva veta social y política erigida por el FPDT: constituirse como gestor colectivo de demandas sociales en otras zonas del Estado de México.

La satisfacción de formar parte de una movilización social constituye una vía para mantener la participación. Por el contrario, Jasper (1998) afirma que existen emociones que pueden influir en la deserción, como la culpa, la vergüenza, la frustración y la decepción. A lo que sostiene Jasper, se puede agregar que tal vez la propia deserción comporte un eco emocional. De nueva cuenta, decisiones sociopolíticas, cognición, dilemas axiológicos y afectos se imbrican y cobran pertinencia sociológica.

Otra veta de reflexión es analizar el vínculo entre emociones y memoria, particularmente cómo a través del recuerdo es significada la participación sociopolítica y, en ese terreno, explorar de qué manera el hecho de haber integrado un movimiento social tiene una resonancia que va más allá de la esfera política, para alcanzar el ámbito de lo privado. Así, al ser parte de la subjetividad, «la memoria no solo es responsable de nuestras convicciones, sino también de nuestros sentimientos» (Todorov, 2000: 26).

Para algunos de los miembros del movimiento en contra de la terminal aérea, la memoria de la participación en esta lucha está revestida de afectos. Uno de ellos es la sensación de empoderamiento, particularmente en el caso de las mujeres, ya que la escisión tradicional entre los géneros - lo público como esfera exclusiva de los hombres y lo privado como reino de lo femeninofue cuestionada a raíz del trastrocamiento vivencial que para ciertas personas representa formar parte de un movimiento social, sobre todo en contextos culturales marcados por una costumbre sexista. El siguiente testimonio refleja cómo participar en la construcción de una identidad colectiva resuena en la misma identidad personal y, en ocasiones, la fortalece:

Creo que en esta lucha hubo algo muy concreto: las mujeres encontraron un espacio sólido o una posición más sólida dentro de la sociedad y dentro de su familia (...). Recuerdo la experiencia de una compañera a la que no le daba chance su pareja de venir a las marchas y que, sin embargo, ella decía: «No, pues yo voy». Cuando ella iba a su casa, pues «aguas», la golpeaban, y eso ella lo comentaba en el micrófono, en las asambleas. Era algo así como que estoy luchando por mi pueblo, pero dentro de mi familia sigo siendo golpeada y humillada, mi dignidad está siendo pisoteada. Posteriormente, tomó valor y dijo: «Tú ya no me vas a golpear, ahora me vas a respetar» (...). Este movimiento dio lugar a muchas cosas, entre ellas, el lugar que las mujeres se ganan, eso resulta ya innegable: la actitud de las mujeres. Aprendimos muchísimo de esta lucha, también de nuestros propios compañeros, los compañeros como pareja y los del movimiento, aprendimos demasiado, también lo hicimos de aquellos que llegaron a Atenco a apoyarnos. (Entrevista a Hortensia, archivo personal, 12 de febrero de 2006) 
Como se ha señalado, los movimientos sociales son una esfera donde se erigen afectos, se reivindican y confrontan valores y se despliegan diferentes estrategias políticas y discursivas. Para quien participa en una lucha sociopolítica, esta se convierte en una fuente de experiencia organizativa y colectiva y, como tal, en un referente de interpretación de futuros acontecimientos políticos y sociales. En Atenco, los antecedentes organizativos de alcance local, junto con la experiencia de montar fiestas y faenas, así como la propia experiencia de la lucha en contra del proyecto aeroportuario, desembocaron en lo que he denominado como un saber organizativo y de resistencia. Este saber -el cual es un acervo de conocimientos sociopolíticos - forma parte del legado de este sujeto colectivo, legado que cuenta con aristas políticas, simbólicas y sociales y que, gracias a la memoria, se ha reproducido entre individuos pertenecientes a diversas generaciones. En el siguiente apartado, se analizará qué vínculo hay entre identidad, afecto y territorio, además de explorar qué emoción actuó como sustrato identitario y como resorte para la movilización en contra de la expropiación.

\section{Emociones, identidad y territorio}

Como se mencionó, las emociones son expresiones culturales que atraviesan la vida social y política. En los movimientos sociales, son no solo medios, sino también fines para la acción en la medida en que son una fuente de satisfacción colectiva e individual, así como de reforzamiento identitario. Hay que subrayar que las emociones son construcciones intersubjetivas fruto de las relaciones sociales, a la vez que influyen en ellas y son dispositivos cognitivos e interpretativos de la realidad - junto con los valores. Comprender el orden intersubjetivo de la afectividad en el terreno de la acción colectiva remite a hablar de las emociones recíprocas y las emociones compartidas (Jasper, 1998). Las primeras son los sentimientos de los integrantes de los movimientos hacia sus propios compañeros de lucha - como el cariño, la lealtad, la solidaridad, el amor- y forman parte de la satisfacción de la protesta. Las segundas son aquellos afectos que se experimentan sin tener a los otros participantes como objeto, sino que se dirigen hacia los adversarios - como el agravio, el enojo o la indignación. Ambas modalidades están interrelacionadas y se gestan en el seno del actor y en relación con el campo de confrontación que el actor ha erigido junto con sus oponentes. El siguiente testimonio ilustra el concepto de emociones recíprocas:

Entre nosotros nos platicábamos, formamos, como le digo, una familia: «Pues a mí me duele esto y a mí me duelo lo otro, ¿cómo le vamos a hacer?». También tuvimos, entre nosotros, nuestras llamadas de atención: "¿Sabes qué? Estás haciendo mal». O sea, que siempre tuvimos comunicación y eso fue lo que nos ayudó a quitar todos los obstáculos que estaban ahí (...). Hay un muchacho que hasta ahorita me dice «mamá Jose», desde el movimiento. Me decía así porque éramos nosotras quienes atendíamos a los más jóvenes y pues ellos, 
los más jóvenes, tenían respeto hacia nosotros. A lo mejor me llamaba mamá porque los jóvenes siempre estaban fuera de casa, pero sentían que nosotras les dábamos apoyo, no igual que sus madres, pero encontraron cariño entre nosotros. (Entrevista a Josefina, archivo personal, 12 de febrero de 2006)

Las emociones recíprocas y las compartidas contribuyen a erigir y reforzar identidades colectivas y, con ello, manifestaciones de solidaridad, elementos de suma relevancia en los procesos de movilización social. Pero ¿qué es la identidad? Por principio, hay que señalar que es una construcción social, pergeñada por prácticas, estructuras y relaciones, por el poder y el conflicto, además de estar embebida de significados. Edificadas espaciotemporalmente, las identidades son el sentido de pertenencia a múltiples espacios y a diversos grupos sociales; su carácter cambiante, dinámico, no excluye que algunos de sus rasgos sustantivos permanezcan a lo largo del tiempo. Un componente medular de la identidad colectiva es la memoria, es decir, el pasado interpretado desde el presente sobre experiencias, sucesos, personajes y símbolos comunes. Es justamente la memoria el sustrato vivo que alimenta las identidades y que posibilita tender un puente entre presente, pasado y futuro. En una dinámica de movilización y conflicto social, la identidad es la que fundamenta el «nosotros», frente al «ellos» _ el adversario_- con su inherente revestimiento político y simbólico.

La naturaleza intersubjetiva de la identidad colectiva conduce a aseverar cómo es edificada en el seno de la vida cotidiana, en ese terreno donde se construyen, comparten y transforman emociones y valores de diversa índole. $\mathrm{Al}$ ser un referente de interpretación del mundo, la identidad es un dispositivo cognitivo cuyo alcance, no obstante, trasciende dicho ámbito:

Una identidad colectiva no es simplemente el diseño de un límite cognitivo. Es, ante todo, una emoción, un afecto positivo hacia otros miembros del grupo social sobre la base de la filiación común. Definirse a uno mismo a través de la ayuda de una etiqueta colectiva implica un mapeo del mundo social tanto afectivo como cognitivo (...) la protesta se convierte en una forma de decir algo acerca de uno mismo y de su moral personal, y encontrar alegría y orgullo en ello. Uno puede tener emociones negativas sobre el papel de la propia identidad, tales como vergüenza o culpa; muchos movimientos están precisamente motivados por la pelea en contra de las identidades estigmatizadas. Lo que es difícil de imaginar es una identidad que sea puramente cognitiva. La fuerza de una identidad viene de su lado emocional. (Jasper, 1998: 24)

El proceso de reconocimiento y heterorreconocimiento inherente a la identidad está imbuido de emociones, en gran medida porque las relaciones sociales que la configuran son lazos emocionales. Posiblemente la solidaridad y la empatía sean expresiones identitarias: soy capaz de ponerme en el lugar del otro, de experimentar empatía, de identificarme con él y, como tal, de solidarizarme. Revilla Blanco (1996) ha planteado cómo la lealtad es sinónimo de la identidad: un individuo es leal a un grupo social en la medida en 
que se siente parte de él; cuanto más grande sea la identificación, mayor será la lealtad. Así como la identidad está revestida de afectos, también lo está de valores: de un ejercicio de autopercepción y de percepción del otro con una carga axiológica.

Hablar de la identidad exige puntualizar el nexo estrecho e indisociable que mantiene con el espacio, el cual es un producto social, político, cultural e histórico, configurado por elementos materiales y simbólicos. El vínculo existente entre espacio y sociedad es de mutua incidencia, aserción que implica que el espacio no es el mero escenario de la acción social y política, sino un factor que, junto con el tiempo, articula las sociedades. Todo espacio apropiado material y simbólicamente tiene un carácter procesal, abierto y dinámico -rasgos que distinguen también la identidad colectiva. La relación entre espacio e identidad es de recíproca influencia, de manera que un cambio en el primero afecta a la segunda y viceversa (Tamayo y Wildner, 2005). Este presupuesto es comprensible ya que, como bien establece Giménez (2009), para poder existir, las identidades requieren de contextos de interacción estables, o sea, mundos socialmente edificados que no son cuestionados, que son dados por descontados y que brindan certezas al ser un orden de normalidad y familiaridad.

Bajo estos lineamientos, se puede sostener que el territorio afectado por los decretos expropiatorios constituye justamente ese contexto de interacción estable, fuente de seguridad ontológica y de confianza. Ese territorio labrado a lo largo del tiempo por sus propios pobladores es un espacio apropiado - material y simbólicamente-, habitado y significado; tejido por los diferentes lazos sociales que en él se han desarrollado, además de la relación que sus habitantes han mantenido con él. El espacio atenquense, al ser objeto de múltiples significaciones, representaciones y prácticas sociales, está embebido de afectos. Uno de ellos es el de topofilia, concepto facturado por $\mathrm{Yi}-\mathrm{Fu}$ Tuan, en el que se conjunta afectividad y lugar:

La palabra topofilia es un neologismo, útil en la medida en que puede definirse con amplitud para incluir todos los vínculos afectivos del ser humano con el entorno material. Dichos lazos difieren mucho en intensidad, sutileza y modo de expresión. La reacción al entorno puede ser principalmente estética y puede variar desde el placer fugaz que uno obtiene de un panorama a la sensación igualmente fugaz, pero más intensa, de la belleza que se revela de improviso. (...) Más permanentemente — pero menos fácil de expresar - es el sentir que uno tiene hacia un lugar porque es nuestro hogar, el asiento de nuestras memorias o el sitio donde nos ganamos la vida. (Tuan, 2007: 130)

Sostengo que la topofilia como manifestación afectiva constituye una emoción estable, erigida a lo largo del tiempo, que conformó la savia que nutrió el shock moral de ejidatarios y residentes una vez emitidos los decretos expropiatorios en Atenco. En otras palabras, el amor hacia la tierra atenquense fue el sentimiento condicionante para la irrupción de emociones como indignación, rabia y temor entre los pobladores una vez que interpretaron que el territorio - y el orden social en él anclado- estaba bajo amenaza. Como apunta Poma 
(2018), el apego al lugar es un sentimiento que coadyuva a la percepción de un problema, además de ser un resorte para la movilización social. Bajo esta óptica, se puede apreciar, de nueva cuenta, cómo las emociones socialmente articuladas constituyen un referente de interpretación.

Resulta necesario preguntarse en qué se fundamentaba la topofilia experimentada por los atenquenses. En primer lugar, hay que mencionar que los territorios afectados por la expropiación encierran un conjunto de lugares apropiados y significados: en él se encuentran la casa, espacios productivos - los ejidos-, sitios de recreo, de prácticas religiosas, de memoria, de actividades políticas y culturales. Se trata de diversos espacios públicos y privados en los que se practica y consagra el habitar. Ya Heidegger (1951) afirmaba que el habitar no se reduce a la vivienda, sino a experimentar resguardo, protección y seguridad en relación con un espacio. Así, los diferentes espacios habitados por los atenquenses constituyen el «estar en el mundo».

De este modo, se puede analizar cómo uno de los ingredientes constitutivos de la identidad colectiva atenquense es justamente el territorio - junto con las prácticas y relaciones sociales que en él y en relación a él se realizan. En consecuencia, una de las emociones que arropan la identidad local es la topofilia, de manera más precisa, se puede afirmar que dicho afecto es un indicio identitario. Así, el apego y el amor al territorio que los habitantes tienen en común - junto con la memoria — han labrado una identidad colectiva de forma dinámica y abierta. Identidad y topofilia fueron dos poderosos resortes para oponerse colectivamente al proyecto aeroportuario. Para que eso fuera posible, sin embargo, resultó imprescindible la densidad de redes sociales y la experiencia organizativa que los habitantes de esta región han confeccionado en el transcurso del tiempo.

Si se parte de la premisa que las emociones y los valores están arraigados en las condiciones sociales de vida de los sujetos, entonces habría que deconstruir aquellos componentes que integran la topofilia. Uno de ellos se refiere al vínculo tierra-trabajo: «De la tierra comemos, de ahí se vende la hoja, se vende el maíz, y cuando no hay ni para comer, se echan unas tortillas y ya comimos» (entrevista a Epifania, archivo personal, 3 de febrero de 2006). En esta misma sintonía: «Nos querían arrebatar la tierra y pues no me pareció justo. Yo a la tierra la amo, yo la trabajo a diario, el campo es mi vida, aunque digan que no deja, yo digo que sí» (entrevista a Claudio, archivo personal, 5 de marzo de 2006). Otro ingrediente relevante es la celebración de fiestas tradicionales y religiosas en el territorio, ritual de interacción medular en la identidad colectiva: «Pues se trataba de nuestra cultura. Aquí hay muchas tradiciones y la verdad es que no estábamos dispuestos a perder nuestras tradiciones, cuando lo del decreto. Ahorita ya se acerca el carnaval, después viene la fiesta de marzo, la cuestión es que Atenco siempre tiene fiesta» (entrevista a Epifania, archivo personal, 3 de febrero de 2006).

Otra parte sustantiva de la topofilia se refiere a la manera en la que los ejidatarios han concebido sus tierras como patrimonio y, con ello, la valoración del trabajo invertido a lo largo de décadas: 
Mi papá es fuerte, se aguantó las ganas de llorar, pero estaba muy triste y me dijo: «El terreno que tengo no es muy grande, pero ¿sabes cuánto tiempo tardó en darnos una cosecha? Años, hija, treinta o cuarenta años, para que yo deje eso, no. Tú has visto cuánto tiempo he trabajado y no con maquinaria, no, de forma natural (...). ¿ No entiende el Gobierno y la gente rica que de aquí comemos y hasta ellos han tragado? Los mantenemos, hija; esta es mi casa, mi terreno, mi vida, y si entra el ejército, voy a ser uno de los primeros en decirles que para tomar mi terreno me van a tener que matar, esa es la única forma en que lo tendrán». (Entrevista a Ana María, archivo personal, 28 de diciembre de 2005)

Ligado a esta noción socialmente facturada de los ejidos como patrimonio, se encuentra el modo en que los pobladores significaron los decretos expropiatorios como la ruptura del orden social erigido por ellos mismos y, por lo tanto, se consideró que su continuidad estaba bajo amenaza. Dicho proceso de reproducción y continuidad social se sustenta en el legado material y simbólico de una generación a otra. El historiador marxista E. P. Thompson (2002) desarrolló el concepto de entramado hereditario para aludir cómo campesinos ingleses regidos por la costumbre local, al heredar la tierra y su derecho de usufructo, en realidad estaban legando roles, relaciones sociales y un sistema de prestigio y estatus. Bajo este argumento, se puede aseverar como hipótesis que la defensa del territorio atenquense representaba el resguardo de un entramado comunitario y su continuidad a las futuras generaciones:

Cuando teníamos que ir a las marchas, yo abrazaba a mis hijos, a mi suegra y me encomendaba a Dios, pensaba, ya vamos a que nos maten, quien sabe si nos maten o regresemos con bien, pero por lo menos vamos a luchar, yo iba a pelear (...). Pensaba, si me matan lo van a hacer por un porvenir, por una cosa valiosa, estoy luchando por mis hijos y por mis nietos. (Entrevista a Epifania, archivo personal, 3 de febrero de 2006)

\section{Conclusión}

A partir de diversas ópticas teóricas sobre el papel de las emociones en los movimientos sociales y de enfoques que enfatizan en la razón subyacente a la acción, se ha sostenido cómo la racionalidad de la acción colectiva está compuesta por creencias, razones, valores y afectos que, como tales, forman parte de los significados que orientan el quehacer sociopolítico. Como se ha señalado, no hay una relación antagónica entre afectividad y razones, ambas forman parte de la manera en que los sujetos erigen e interpretan la realidad social.

El movimiento atenquense se originó en parte por el shock moral una vez emitida la expropiación de los terrenos. Este hecho, junto con la existencia de lo que llamo un saber organizativo y de resistencia, contribuyó a la constitución de este sujeto. El shock moral puede ser visto como un incentivo emocional para la participación en la lucha en contra del aeropuerto. Esta emoción, imbuida de ingredientes axiológicos, se alimentó de otro afecto estable tejido a lo largo del tiempo: la topofilia, es decir, el apego al territorio. La topofilia, 
a su vez, se instituyó a partir de que los ejidos han sido considerados por los atenquenses como una fuente de trabajo y como un patrimonio, donde el territorio es el soporte material y simbólico de numerosas prácticas y relaciones sociales. He aseverado cómo el territorio no es un simple escenario de la acción, sino un elemento constituyente de la identidad colectiva. En consecuencia, la defensa del territorio representaba el resguardo de un orden social edificado en y en relación con el espacio. Asimismo, la movilización contra el aeropuerto constituyó la defensa de un entramado hereditario.

La investigación sociológica sobre el rol de las emociones en la movilización remite a varios interrogantes: ¿hasta dónde es factible generalizar sobre el papel afectivo en dichos procesos?, ¿qué herramientas metodológicas pueden ser empleadas? Es importante recalcar que las emociones son construcciones culturales e históricas, sujetas a particularidades y modificaciones; si bien hay afectos que son universales, su configuración y vivencia pueden variar. Es por ello que resulta necesario y pertinente la realización de investigaciones empíricas sobre el nexo emotividad-acción colectiva con el objetivo de encontrar diferencias y similitudes en diversos escenarios de conflictividad y con ello erigir, siguiendo a Weber, tipos ideales que posibiliten ampliar los instrumentos teóricos ya existentes.

Las estrategias metodológicas en el estudio de las emociones no son unívocas, la tradición etnográfica es útil al posibilitar adentrarse en los significados, relaciones y prácticas sociales de diversa naturaleza, así como en las identidades, la memoria y el poder. Justamente para el estudio del sujeto atenquense, fueron aplicadas técnicas etnográficas con el propósito de alcanzar profundidad, pese a las limitaciones que esto supone en términos de generalización. Analizar afectos comporta la hermenéutica doble (Giddens, 1998): por una parte, la interpretación de la realidad que hacen los actores y, por otra, la efectuada por el sociólogo sobre la base de un modelo teórico. Se trata de un encuentro de subjetividades y de diferentes marcos de sentido donde — sostengo - el deber del analista es dual: aproximación al actor para entablar rapport y mantener la necesaria distancia para explicar científicamente lo anterior a partir de un ejercicio constante de lo que se puede denominar autovigilancia epistémica. Pese al valor metodológico que ofrece la etnografía, herramientas cuantitativas, como cuestionarios, pueden ser otro insumo para analizar la veta afectiva e interpretativa que engloba la movilización sociopolítica.

Finalmente, es necesario evitar lecturas reduccionistas: las emociones no son la única variable que condiciona la movilización, ingredientes políticos, históricos, económicos y geográficos se yuxtaponen para instituir un fenómeno que se distingue por su carácter multidimensional.

\section{Referencias bibliográficas}

Авiтвоl, P.; Botero, F. (2005). «Teorías de elección racional: estructura conceptual y evolución reciente». Colombia Internacional (62), 132-145. <https://doi.org/10.7440/colombiaint62.2005.08>. 
Butler, Judith (2006). Vida precaria. El poder del duelo y la violencia. Buenos Aires: Paidós.

Collins, Randall (2009). Cadenas rituales de interacción. Ciudad de México: Anthropos.

Elster, Jon (2002). Alquimias de la mente. La racionalidad y las emociones. Barcelona: Paidós.

Gamson, William (1992). Talking politics. Cambridge: Cambridge University Press. Giddens, Anthony (1998). La constitución de la sociedad. Buenos Aires: Amorrortu. Giménez, Gilberto (2009). Identidades sociales. Ciudad de México: Conaculta.

Heidegger, Martin (1951). Construir, habitar, pensar. <http://www.geoacademia.cl/ docente/mats/construir-habitar-pensar.pdf>. Revisado el 11 de octubre de 2018.

Hochschild, Arlie (1979). «Emotion work, feeling rules and social structure». American Journal of Sociology (85), 551-575. $<$ https://doi.org/10.1086/227049>.

INEGI (1990). Censo de población y vivienda. Ciudad de México: INEGI.

- (2000). Censo de población y vivienda. Ciudad de México: INEGI.

- (2010) Censo de población y vivienda. Ciudad de México: INEGI.

JASPER, James (1998). «The emotions of protest: affective and reactive emotions in and around Social Movements». Sociological Forum (13), 397-424.

- (1998). «Las emociones de la protesta: emociones afectivas y reactivas dentro y en torno a los movimientos sociales». <http://www.redmovimientos.mx/2016/ wp-content/uploads/2017/12/Las-emociones-de-la-protesta-emociones-afectivasy-reactivas-dentro-y-en-torno-a-los-movimientos-sociales.-James-M.-Jasper.pdf $>$. Revisado el 20 de agosto de 2018.

- 2012. "Las emociones y los movimientos sociales, veinte años de teoría e investigación». Revista Latinoamericana de Estudios sobre el Cuerpo, Emociones y Sociedad (10), 48-68.

KeMPER, Theodore (1978). A social interactional theory of emotions. Nueva York: Wiley.

- (2001). "A structural approach to Social Movements Emotions». En: Goodwin, Jeff; Jasper, James; Polleta, Francesca (comps). Passion politics. Chicago: The University of Chicago. <https://doi.org/10.7208/chicago/9780226304007.003.0004>.

Kuri Pineda, Edith (2010). «El movimiento social de Atenco: experiencia y construcción de sentido». Andamios (14), 321-345. <https://doi.org/10.29092/uacm.v7i14.110>.

Linares, Francisco (2004). «Hawks, zealots and hypocrites but not free riders. The logics of cooperation in Llano del Beal». Rationality and Society (16), 437-476. <https://doi.org/10.1177/1043463104044683>.

- (2007). «El problema de la emergencia de normas sociales en la acción colectiva». Revista Internacional de Sociología (46), 132-160. $<$ https://doi.org/10.3989/ris.2007.i46.7>.

Markwell, G.; Oliver, P. (1993). The critical mass in collective action: a micro-social theory. Cambridge: University Press.

Olson, Mancur (1992). La lógica de la acción colectiva. Bienes públicos y la teoría de grupos. México: Limusa.

Paramio, Ludolfo (2005). «Teorías de la decisión racional y de la acción colectiva». Sociológica (57), 13-34.

Petersen, Roger (2008). «Usos estratégicos de las emociones en los conflictos. Emociones e intereses en la reconstrucción de Estados multiétnicos». En: Cante, 
Freddy (ed.). Argumentación, negociación y conflictos. Bogotá: Universidad del Rosario.

Poma, Alice (2018). «El papel de las emociones en la respuesta del cambio climático». Interdisciplina (15), 191-214. <https://doi.org/10.22201/ceiich.24485705e.2018.15.63843>.

Revilla Blanco, Marisa (1996). «El concepto de movimiento social: acción, identidad y sentido». Última Década (005), 1-18.

Robles, José Manuel (2007). «Bajo el signo de la moral. ¿Son útiles los incentivos morales para explicar la acción colectiva?». Revista Internacional de Sociología (46), $185-204$. <https://doi.org/10.3989/ris.2007.i46.9>.

SABIdo, Olga (2012). "La confianza y los tiempos de incertidumbre». En: León, Emma (coord.). Virtudes y sentimientos sociales para enfrentar el desconsuelo. Ciudad de México: CRIM.

Smelser, N. (1962). Teoría del comportamiento colectivo. México: Fondo de Cultura Económica.

SnOw, David; BENFORD, Robert (2006). «Ideología, resonancia de marcos y movilización de los participantes». En: Chinu, Aquiles (coord.). El análisis de los marcos en la sociología de los movimientos sociales. Ciudad de México: Universidad Autónoma Metropolitana.

Tamayo, Sergio; Wildner, Kathrin (2005). Identidades urbanas. Ciudad de México: UAM.

Thompson, E. P. (1981). Miseria de la teoría. Barcelona: Crítica.

- (2002). Thompson. Obra esencial. Barcelona: Crítica.

Todorov, Tzvetan (2000). Los abusos de la memoria. Barcelona: Paidós.

Tuan, Yi-Fu (2007). Topofilia. Un estudio de las percepciones, actitudes y valores sobre el entorno. España: Melusina. 